\title{
The Dynamics of Public Attention: Agenda-Setting Theory Meets Big Data
}

\author{
W. Russell Neuman, Lauren Guggenheim, S. Mo Jang, \& Soo Young Bae \\ Communication Studies, University of Michigan, Ann Arbor, MI 48109, USA
}

\begin{abstract}
Researchers have used surveys and experiments to better understand communication dynamics, but confront consistent distortion from self-report data. But now both digital exposure and resulting expressive behaviors (such as tweets) are potentially accessible for direct analysis with important ramifications for the formulation of communication theory. We utilize "big data" to explore attention and framing in the traditional and social media for 29 political issues during 2012. We find agenda setting for these issues is not a one-way pattern from traditional media to a mass audience, but rather a complex and dynamic interaction. Although the attentional dynamics of traditional and social media are correlated, evidence suggests that the rhythms of attention in each respond to a significant degree to different drummers.
\end{abstract}

doi:10.1111/jcom. 12088

McCombs and Shaw (1972) famously introduced their notion of media agenda-setting by quoting Cohen's (1963) epigram: “The press may not be successful much of the time in telling people what to think, but it is stunningly successful in telling its readers what to think about." "What to think" refers to the traditional paradigm of persuasion and attitude change research including the counterintuitive findings of generally low correlations between media exposure measures and attitude change (Klapper, 1960). But McCombs and Shaw added a new element focusing on "what to think about" - the analysis of the public agenda. In an intriguing exemplar of Kuhnian is the adjective derived from the name Thomas Kuhn (1962) which is included in the bib Kuhnian theoretical evolution (1962), they proposed a theoretical puzzle (modest evidence of media effects) and the basic elements of a methodology for resolving the puzzle (shifting the focus from public opinion and political preference to the "agenda" of important problems and issues). The resulting agenda-setting literature grew quickly and dramatically. McCombs (2004) in a recent review made note of the existence of over 400 agenda-setting studies.

The basic causal model posits that correlations between aggregated measures of media issue coverage and public opinion survey measures of issue importance

Corresponding author: W. Russell Neuman; e-mail: rneuman@umich.edu 
at a single point in time represent evidence of media agenda-setting. Subsequent studies refined the model by examining the agenda-setting correlation for different types of issues, different types of media, different types of audiences, and different time lags between media coverage and audience response (Dearing \& Rogers, 1996; McCombs, 2004; McCombs \& Shaw, 1993; McCombs, Shaw, \& Weaver, 1997; Wanta \& Ghanem, 2007). A few in this tradition tackled the difficult prospect of measuring both media agendas and public agendas over time with careful attention to the issue of causal direction (Brosius \& Kepplinger, 1990; Burstein, 1985; Cohen, 2008; Fan, 1988; Kellstedt, 2003; Neuman, 1990). But the number of such analyses was so small that they were eliminated from a meta-analysis with the notation: "Because the majority of agenda-setting studies have used Pearson correlations, eliminating these few time-series studies did not substantially reduce the number of studies included in our analysis" (Wanta \& Ghanem, 2007, p. 43). McCombs and Shaw (1972) considered the possibility that correlations between media and public agendas could represent causation in the reverse direction with journalists, in effect, anticipating or estimating public interests but rejected that premise as implausible.

In a world of evolving digital media and online publics, the dynamics of issue agendas are becoming more complex. Importantly, because both the traditional and social media are online they are equally accessible to time-series analysis. Sophisticated analyses of overtime dynamics are no longer so difficult to conduct that their scarcity may lead them to be ignored. The phrase "big data" seems to be catching on as a generic label for data and analyses of this general type. Early promoters of these new directions, although full of enthusiasm and perhaps a bit of missionary zeal, are generally well aware of the many limitations and biases of these methodologies and acknowledge that these new research opportunities will complement and expand, rather than replace, more traditional methods (Bollier, 2010; Boyd \& Crawford, 2012). One notable problem in this domain is that big data systems effortlessly generate large numbers of colorful visualizations of text patterns and overtime trend graphs so as a result analysts may be inadvertently seduced into a reliance on description rather than theory testing (Borrero \& Gualda, 2013). Distractions aside, parallel time-series analysis of big data offers a critical test of extant and evolving theories of public opinion and public attention. Agenda-setting theory meets big data.

\section{Who sets the agenda in the digital age?}

With but a few keystrokes and mouse clicks any audience member may initiate a new discussion or respond to an existing one with text or audio, or perhaps images and even video. Transmitting requires minimal effort, and once one is digitally equipped, it is virtually costless. To posit that the power of the public agenda has swung from media elites and establishment institutions to the citizenry would be naïve. But the foundational conceptions of self-evident media agenda-setting may benefit from some fresh rethinking. The fundamental question may best be characterized as this: Under 
what conditions do digitally connected publics respond and when do those responses meaningfully impact the broader public and media agendas and the framing of public issues? Before the reintroduction of the term by Kim and Lee (2006), the notion of reverse agenda-setting meant simply that journalists may be responding to actual or perceived public interests and thus the public agenda could be seen as preceding and influencing the media agenda (McCombs, 2004).

Influences on the formation of the media agenda are outlined by Shoemaker and Reese's (2014) five-tier conceptual model. Their five factors contributing to the media agenda include individual journalists, media routines, organizational factors, social institutions, and cultural/ideological considerations. Although this model acknowledges the possibility that individuals, such as government officials or public relations practitioners, may affect the media agenda and that the cultural factors may simultaneously influence both journalists and their audiences, the general public is not identified as a significant influence in the model and the notion of reverse agenda-setting is not raised. Another related literature focuses on the concept of intermedia agenda building, which refers to the effects of institutional media agendas on each other (Golan, 2006). A number of studies attribute intermedia communication processes to common interests and sources among journalists (e.g., pack journalism) as well as news organizations' willingness to "report on a report" (Denham, 2010, p. 315). Especially when reporting sensitive issues that might offend interest groups (e.g., advertisers), news agencies often cover the issues by citing the original report to make themselves appear relatively neutral. Research has demonstrated this intermedia agenda building in the correlation of the agendas of three evening television programs with that of the New York Times the following morning (Golan, 2006). More recently studies have begun to observe the parallels between online "buzz" and mass media content (Karpf, 2008; Lee, 2007; Wallsten, 2007).

The emergence of social media has generated renewed attention to the reverse agenda-setting idea. Interpersonal conversations about public issues have always been an important part of the dynamics of the public sphere (Habermas, 1962; Katz \& Lazarsfeld, 1955). But now they are increasingly empirically accessible for analysis. Given the technical opportunity and most often the absence of enforced censorship, citizens of the industrialized and developing worlds, it appears, are ready and willing to speak out. The statistics here represent a moving target, but even a sampling from recent years creates a compelling picture. In 2011, Blogpulse estimated that there are more than 172 million identified blogs and more than 1 million new posts being produced by individuals each day (Blogpulse, 2011). Twitter has 100 million active users logging in at least once a month and 50 million active users every day (Taylor, 2011). Of course, blogs and social media are famously full of "pointless babble" and self-promotion. One study in 2009 focusing on Twitter ranked "pointless babble" at $40 \%$ and "conversation" at 38\% ("tweets that go back and forth between folks, almost in an instant message fashion, as well as tweets that try to engage followers in conversation, such as questions or polls") and current news at $4 \%$ (Kelly, 2009). So, given the tremendous size of this electronic conversation, even if cats playing pianos 
seem to be the most popular, there is extensive and diverse political conversation and commentary as well.

It would be problematic, of course, to simply equate online tweets, blogs, and comments to "public opinion" in general. Social media users are not demographically representative and diverse social media platforms undoubtedly develop local cultures of expressive style which will influence the character of what people choose to say. But in-person, telephonic, and online surveys of multiple choice self-reports also fail to capture this elusive gold standard of public opinion without bias and distortion. The social media represent an important, perhaps increasingly important, instantiation of public opinion just as the outcomes derived from those who choose to answer surveys and those who choose to vote do.

The standing answer to the question "who sets the agenda" is that the traditional media set it. Online news sources which represent the online face of traditional broadcast and print media dominate public attention to news online (Hindman, 2009). By one estimate only $5 \%$ of bloggers commenting on public affairs do anything approaching independent journalism and information gathering - it is mostly simply a reaction to mainstream media content (Lenhart \& Fox, 2006). In language that often proposes to celebrate the new citizen journalists and community agenda-setters, lists of the "exemplary" cases of reverse agenda-setting are less than compelling. Most such top 10 lists in the American context point to the case of bloggers keeping the issue of Senator Trent Lott's awkward racial remarks alive in 2002 and Dan Rather's troublesome sources for his story on candidate George W. Bush's Air National Guard experience in 2004, resulting in both stories being addressed by the traditional media. Other examples, after those two significant stories, are rather marginal, dealing with technical issues in Apple and Dell products and other cases where it was unclear where a story was initiated (Haskins, 2007). A study of top 10 cases of reverse agenda-setting in Korea included a few significant political cases but most dealt with minor scandals or bizarre behavior including the mishandling of babies in an obstetrics ward, poor quality school lunches, and a kerfuffle over a dog in a train station (Kim \& Lee, 2006). Anecdotal examples do not represent systematic evidence, but the explosive growth of social media and the increasingly complex dynamics of intermedia agenda building merit further attention.

RQ1: Who sets the agenda? Does evidence of a time-series linkage run from traditional media to social media or the other way around?

Agenda-setting research has increasingly focused on a second and related question - not just how important is an issue, but how the issue is framed and which issue attributes are emphasized (Chong \& Druckman, 2007; Entman, 1993). This is often referred to as second-level agenda setting (McCombs, 2004), or simply framing research. Such questions are particularly important in making sense of patterns of support for alternative policy responses to public problems. The classic exemplar concerning the framing of the unemployment issue, for example, contrasts an issue frame emphasizing ill-prepared workers lacking in job skills with structural and 
industrial policy problems in an increasingly global economy (Gilens, 1999; Iyengar, 1991). Another example is the relative emphasis in the discussion of gun legislation on constitutional rights or alternatively on safety. Framing theory has become increasingly central to the study of public opinion and public attention. Chong (1993, p. 870), for example, labels framing "the essence of public opinion formation" as it "lies in the distillation or sorting out of frames of reference on political issues. New issues in the public eye are typically subject to a variety of interpretations. In the course of public debate, however, public opinion leaders establish common frames of reference for discussing the issue and 'neutralize,' or render irrelevant, alternative interpretations.” Bennett (1990), Entman (2004), and Zaller (1992), for example, have forcefully emphasized how elite leadership in issue framing can effectively neutralize alternative interpretations. However, Gamson (1992) and also Druckman and Nelson (2003) point out that these framing effects are highly conditional and that publics frequently persist in alternative perspectives despite frequent repetition of elite frames in the media. Importantly, Kellstedt (2003) and Shah, Watts, Domke, and Fan (2002) expand the research horizon to explore the dynamics of oppositional frames over time. In their experimental work, Druckman and Nelson (2003) conclude that framing effects are short-lived, dissipating after 10 days. While these questions are about length-of-effect, time-series data is optimally equipped to answer similar overtime questions in a natural setting. Accordingly, we ask:

RQ2: Who frames the public issues of the day? Does evidence of a time-series linkage of issue framing run from traditional media to social media or the other way around?

\section{Method}

Given the diversity and complexity of what could be characterized as serious matters of the public sphere, we picked as our starting point an evolved list of 29 political issues in the study of American politics which grew primarily out of the American National Election Studies (www.electionstudies.org). Over the years, voting researchers asked citizens to list all of the "important issues facing the country" and the issues were transcribed verbatim and then carefully coded into a convergent summative list. Particulars like Watergate and Vietnam come and go but the broader themes are remarkably stable over time. There are six overarching categories from economics and social welfare (national debt, welfare) through foreign affairs (Iraq, trade with China) and social issues (same-sex marriage, abortion) to environmental issues (global warming).

For each issue, we derived a set of four to nine key identifying terms or phrases unique to that issue for purposes of searching the full text of Twitter, blogs, forum commentaries, and traditional media news stories. Thus, for example, the category "unemployment/jobs" was defined by Boolean search terms: "unemployment OR employment," “jobs NOT Steve Jobs," "underemployment," “job growth," “job creators," and so forth. A reference to one or more of the search terms anywhere in the content of an individual article or posting was considered a reference to the 
issue. Using the keyword search, we compiled the number of articles and postings that contained the terms for each day over the course of the year. We did this for each issue in each medium. These constituted our issue vectors. The complete list of policy issues and associated search-phrase strings is available from the authors.

We contracted with the Canadian firm Sysomos for access to the Twitter "firehose" of an estimated 100 million active users, archives of approximately 160 million active blogs, and 300,000 forums and message boards. Importantly, Sysomos also monitors the electronic footprint of traditional media including local newspaper and broadcast websites as well as the national broadcast and print media. Sysomos identifies blogs, forums, and news sites by their technical features, crawling the web to find each. The company gathers news from copyrighted data feed providers, excluding the public comments that accompany it, and gathers forum threads from forum data providers. To be considered a blog, a site must have an RSS feed (Really Simple Syndication), a time stamp for each posting, an ordering of posts where the newest ones appear first, and each post must have a permalink, title, and body. This enterprise grew out of academic research at University of Toronto that computer scientists dubbed BlogScope, which was designed to track the growth and decline of public discussion focusing on what they called "information bursts" (Bansal \& Koudas, 2007). Additional Twitter data for Table 4 was sourced from Topsy Labs Inc.

One impediment to collecting valid, high-quality data is the presence of spam; finding only original content written directly by individual users of these sites (and not bots) can be difficult. Sysomos discards as spam $40 \%$ of what it crawls across all outlets, including the four we focus on in this article. The company uses four main methods to determine whether social or traditional media posts are spam or actual content. One method is to compare content against lists of known spammers. A second is to filter based on patterns known to be spam, such as suspicious links and nonsense content. A third method is to use machine learning that classifies spam, and the final method is to use network analysis to eliminate the patterns of spam behavior that can be detected by interconnected networks of users or links (e.g., link boosting).

\section{Results}

We focus initially on the 29 "most important issues" vectors (which represent broadly defined policy clusters) from both the traditional print/broadcast media and the social media - specifically, Twitter, blogs, and forums/discussion boards - in English and geographically based in the United States for calendar 2012. Our data consist of the daily volume of tweets, online news articles, blog posts, and discussion board posts for each issue. Days are an appropriate unit because our interest is in capturing the dynamics of attention to issues over time - agenda setting - and not in just trying to determine with which medium a story originates. At the level of a day, the differences between time zones and dynamics due to initial awareness of a story or event are mitigated and also provide us with enough stories and posts in the time period to conduct 
a meaningful analysis. On a typical day, for each of the issue clusters, there would be about 5,000 articles in print/broadcast media, 10,000 tweets, 600 blog posts, and 2,000 discussion board posts that mentioned the issue (as measured by our Boolean search) at least once. In all of these summary statistics, it should be understood that we are not confronting, for example, 5,000 unique and independent articles in the broadcast and print press on the topic at hand. The same article from perhaps the Associated Press or another wire service will be released by multiple sources if judged to be newsworthy. Likewise, much of the social media data represents a retweeting of an original 140 -character post or a comment on someone else's posted comment. But that is, in effect, the point of the analysis - a comparative analysis of the dynamic resonance of issues and issue frames in traditional professional media compared with the evolving public social media.

\section{Issue vectors}

For the current analysis, we combine the Twitter, blog, and discussion-forum data and simply contrast traditional media with an aggregate index of social media. Our baseline average for the 29 issues is 13,362 social media commentaries, and 4,573 traditional news stories in television, radio, print, and corporate online news published nationally for a typical day. As presented in Table 1, the average ratio of attention level between social and traditional media in raw numbers is about 3 to 1 , yet there is great variation around that overall mean depending upon the issue. It appears that the social media are more responsive to public order and social issues and less responsive to the abstractions of economics and foreign affairs. There is significant variation within these broadly defined policy domains as well. While economic indicators are generally less resonant, the issues of jobs, welfare, and healthcare costs appear to be highly salient in social media. The issues of immigration, the Arab Spring, and the ongoing conflicts in Iraq and Afghanistan also appear to draw public response to these otherwise remote matters of foreign affairs.

Because of our interest in the dynamics of agenda-setting, our focal point was a comparison of trend lines of online attention or "buzz" concerning the policy issue. Figure 1 illustrates a typical policy question, the issue of jobs and unemployment for the 366 days (leap year) of 2012. The jobs issue represented a fundamental element of broad concern related to the economic recovery; it was also a matter of contested partisan debate in the election process, in which the professional media and the public responded to the multiple impulses of real-world information, such as the release of job statistics or a prominent campaign speech.

The frequency of mentions in the social media is significantly greater than in the traditional media (8.6 times in the case of the jobs issue), so our analyses present the normalized attention vectors, by dividing the daily volume by the daily average for the year so that the curves can be easily compared as they vary above and below the recoded average level of one. On visual inspection of the top of Figure 1, we see that both the traditional and social media exhibit a weekly cycle in which the references are predictably lower on weekends (about one third of weekday levels for the 
Table 1 Ratio of Social Media to Traditional Media Comments

\begin{tabular}{|c|c|c|c|}
\hline Issue Area & Ratio & Specific Issue & Ratio \\
\hline \multirow[t]{9}{*}{ Economics } & 1.5 & (1) Unemployment/jobs & 8.6 \\
\hline & & (2) Unemployment/recession & 1.3 \\
\hline & & (3) Deficit/national debt & 1.6 \\
\hline & & (4) Energy costs & 1.7 \\
\hline & & (5) Finances/money/housing & 1.1 \\
\hline & & (6) Health care costs & 4.4 \\
\hline & & (7) Wall Street/corporate & 0.5 \\
\hline & & (8) Taxes/tax reform & 2.4 \\
\hline & & (9) Welfare/poverty/inequity & 4.2 \\
\hline \multirow[t]{6}{*}{ Foreign affairs } & 2.3 & (10) Iraq/Afghanistan & 2.6 \\
\hline & & (11) Terrorism & 1.5 \\
\hline & & (12) Defense/national security & 1.5 \\
\hline & & (13) Middle East/Arab Spring & 4.0 \\
\hline & & (14) Global trade/China & 1.9 \\
\hline & & (15) Immigration & 6.3 \\
\hline \multirow[t]{4}{*}{ Government } & 1.7 & (16) Partisan polarization & 1.1 \\
\hline & & (17) Lobby/special interests & 1.3 \\
\hline & & (18) Education & 2.6 \\
\hline & & (19) Natural disaster & 2.9 \\
\hline \multirow[t]{3}{*}{ Public order } & 2.7 & (20) Crime & 1.2 \\
\hline & & (21) Drugs & 8.9 \\
\hline & & (22) Gun control/gun rights & 7.0 \\
\hline \multirow[t]{5}{*}{ Social issues } & 8.3 & (23) Race/racism & 4.9 \\
\hline & & (24) LGBT & 11.1 \\
\hline & & (25) Gender sexism & 8.3 \\
\hline & & (26) Abortion & 11.4 \\
\hline & & (27) Birth control & 10.0 \\
\hline \multirow[t]{2}{*}{ Environment } & 0.8 & (28) Environment & 0.9 \\
\hline & & (29) Climate change & 3.6 \\
\hline 29 Issue average & 2.9 & & 2.9 \\
\hline
\end{tabular}

traditional media and two thirds for the social media). Thus, we applied an additional day-of-week correction - seven different weight corrections were created and applied based on the ratio of the mean of the specific day of week to the overall mean for the whole year. Such smoothing algorithms are often used in time-series analyses of this type for weekly or seasonal variation, which would otherwise generate a potentially spurious correlation between the two vectors as illustrated at the bottom of Figure 1. The overall time-series correlation between the traditional media and the social media drops from $r=.56$ to $r=.22$ after the correction ( $\alpha<.05$ in both cases).

The corrected curves for traditional and social media at the bottom panel of Figure 1 reveal several patterns. First, blogs and tweets are more volatile and spike 

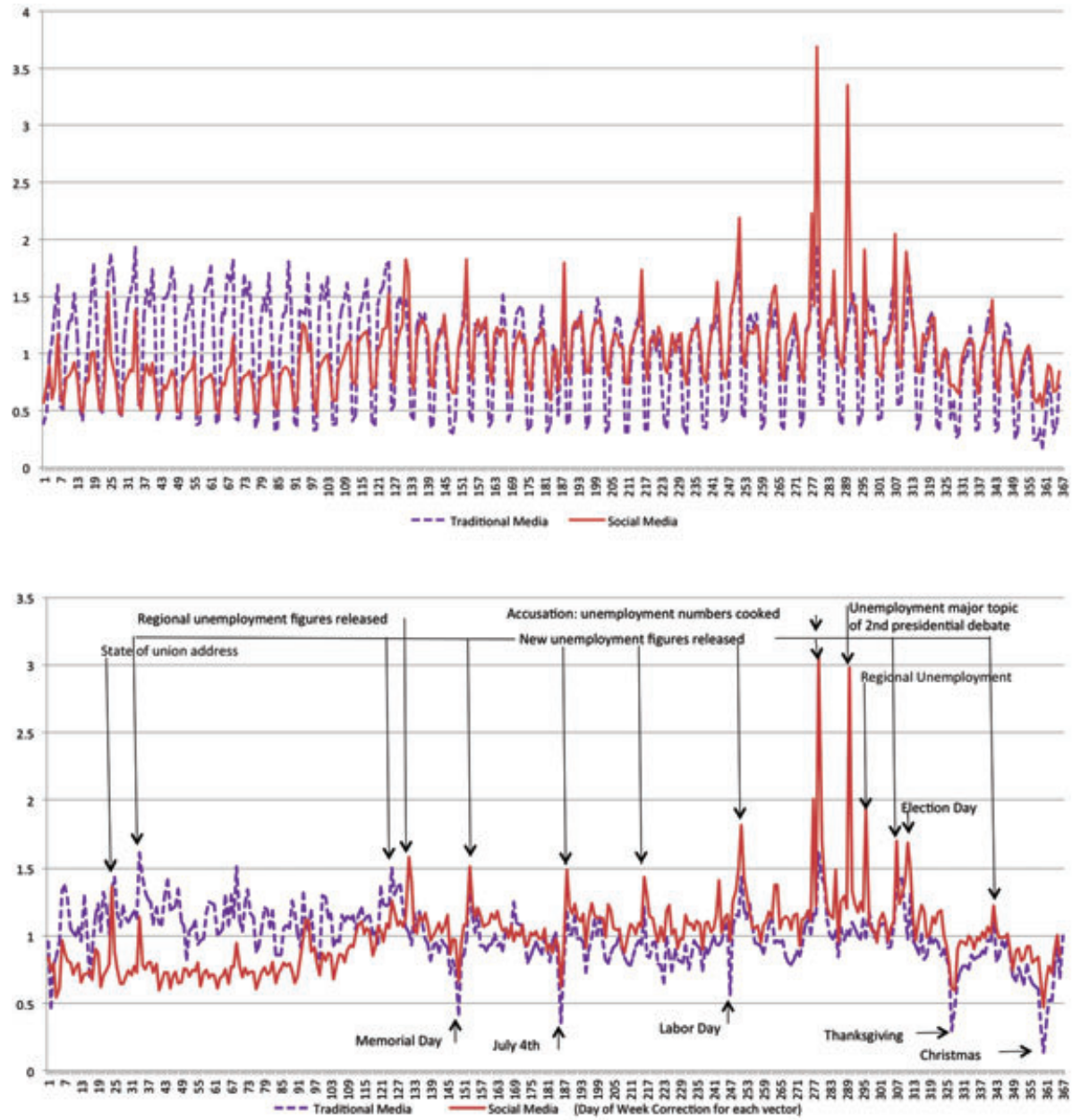

Figure 1 Trends in attention to jobs/unemployment issue in 2012, uncorrected and corrected. Notes: Data are normalized (i.e., mean scaled) and corrected for day of the week prior to analysis.

more dramatically up to three times the daily average volume, while the fixed broadcast minutes and newspaper column inches limit the variation in the traditional media (often including the repurposed online news stories). Second, there is a gradual trend of increased attention to the jobs issue in the social media as the election approaches (a common finding in opinion polling), contrasted with a more stable overall level of attention in the traditional media throughout the year. The general pattern in 2012 was that after a long delay, unemployment numbers finally fell to new 3- and 4-year lows. The economy and job growth were major partisan elements of the election campaign, so the high point of public attention (and traditional media) was the highly public accusation, made by former General Electric CEO Jack Welch, 
that the positive unemployment trends had been "cooked" for political purposes by the Obama administration. Overall, for the issue of jobs at least, it appears that traditional and social media seem to respond in ways similar to the various impulses of new information, public debates about job growth and the appropriate policies to bring it about.

\section{Covariation of issue vectors}

Before testing the agenda-setting dynamics with Granger analysis, it is useful to review the raw correlations, that is, the same-day covariations among social and traditional media without any lags (Table 2). This helps to put in perspective the characteristic magnitudes of time-series correlations and the amount of temporal "noise" in the data. Because of all the independent intervening causal dynamics, we would not expect a covariation lagged by several days to be any higher than contemporaneous covariation. The average correlations are not particularly high among social media $(r=.51$, corrected), or between traditional and social media $(r=.48$, corrected). We also find substantial variation in these correlations between different issue clusters.

\section{The dynamics of agenda-setting}

We have at hand 29 pairs of time-series data vectors for the traditional media and social media that measure daily attention levels for each of the 366 days of calendar 2012. In the interest of testing the temporal order of agenda setting between traditional and social media using the issue vectors, we rely on the methodological framework of Granger causality. Frequently used by econometricians, Granger

Table 2 Correlation of Issue Attention Dynamics Among Media for 29 Issues

\begin{tabular}{|c|c|c|c|c|}
\hline & $\begin{array}{c}\text { Average } \\
\text { Correlation } \\
\text { Among } \\
\text { Social Media }^{\mathrm{a}}\end{array}$ & $\begin{array}{c}\text { Average } \\
\text { Correlation } \\
\text { Among Social } \\
\text { Media (Day of } \\
\text { Week Corrected) }\end{array}$ & $\begin{array}{c}\text { Average } \\
\text { Correlation } \\
\text { Between } \\
\text { Traditional } \\
\text { Media and } \\
\text { Social Media }\end{array}$ & $\begin{array}{c}\text { Average } \\
\text { Correlation } \\
\text { Between } \\
\text { Traditional } \\
\text { Media and } \\
\text { Social Media } \\
\text { (Day of Week } \\
\text { Corrected) }\end{array}$ \\
\hline Overall & .57 & .51 & .54 & .48 \\
\hline Econ and social welfare & .61 & .52 & .58 & .47 \\
\hline Foreign affairs & .53 & .53 & .41 & .40 \\
\hline Government functioning & .63 & .56 & .70 & .60 \\
\hline Public order & .61 & .62 & .55 & .62 \\
\hline Social issues & .49 & .46 & .35 & .33 \\
\hline Environment & .53 & .40 & .64 & .45 \\
\hline
\end{tabular}

${ }^{a}$ Data were corrected for day of the week prior to correlations. All coefficients were significantly different from zero at the .001 level. 
causality draws from the work of Norbert Wiener (1956) and Clive Granger (1969). A measure $x$ is said to "Granger cause" a measure $y$, if $y$ can be better predicted from past values of $x$ and $y$ together, than from past values of $y$ alone (Freeman, 1983). Thus, we would expect the level of public commentary in the social media on gun control on one day, for example, to be roughly predicted by the level of commentary from the days preceding (the autoregressive function). If the spikes in traditional news media on gun control in preceding days predict the levels of social media commentary on gun control, over and above its inertial autoregressive function, we would conclude that the attention in traditional media Granger caused the level of social media attention for that issue. As Granger notes:

"Applied economists found the definition understandable and useable and applications of it started to appear. However, several writers stated that 'of course, this is not real causality, it is only Granger causality.' Thus, from the beginning, applications used this term to distinguish it from other possible definitions" (quoted in Seth, 2007).

In other words, Granger causality can show that the change in the volume of one trend preceded the change of values of another, but cannot show to what extent other events outside the model precipitated both sets of values.

In the traditional execution of Granger time-series regressions, one tests each vector autoregression (VAR) for stationarity - to identify potential trends, cycles, and seasonal variations. The formal test determines whether the eigenvalues of the companion matrix fall within the unit circle, indicating a stationary autoregression (Becketti, 2013). The basic idea is that an impulse event, such as a mass shooting, raises the level of attention in the social media and traditional media for a while and then the attention level gradually returns to the long-term average. One would assume, for example, that the events of 11 September 2001, changed American public opinion and attention with effects lasting beyond a decade. But such events and issues are rare. Most events and public speeches or debates have a half-life of impact measured in days. We found that none of our 29 VARs failed to pass the test of stationarity for 2012.

Next, we determined the appropriate number of lagged independent variables in the regression. Although the optimal number used in previous agenda-setting research varies substantially by both issue and medium (Brosius \& Kepplinger, 1990; Wanta \& Hu, 1994), recent studies with daily data suggest agenda-setting often occurs in a week or less (Roberts, Wanta, \& Dzwo, 2002; Wanta, 1997). In particular, in a study of agenda-setting and online issue salience, Roberts et al. (2002) found that the lag between traditional news and online discussion varied from 1 to 7 days, with day 7 producing the most effects. Given the nature of our data, a time lag that is too short may not sufficiently capture the temporal order of attention to an issue between traditional and social media, whereas a time lag that is too long may be ineffective, due to the danger of the relationship "dissipating over time" (Chaffee, 1972). On the basis of these premises, we utilized statistical tests to confirm the appropriate number of lags. The log likelihood function (a likelihood ratio test), as well as all four criteria 
commonly applied for lag selection (FPE, AIC, HQIC, and SBIC) (Becketti, 2013) indicated that 7 days represent an optimal lag for our analyses.

We used Granger analyses to test whether the past 7 days of both traditional and social media attention levels together predict the next day of traditional media attention significantly better than the previous 7 days of traditional media attention levels alone, as measured by the Wald test. We then examine the traditional agenda-setting direction by regressing the same variables in the reverse direction. For each analysis, we statistically control for each day of the week from the weekday cycle mentioned above in the description of Figure 1. An interesting and important property of Granger analysis is that it allows for identification of "mutual reciprocal Granger causation," rather than (as Kellstedt puts it) formulating the question as whether chickens cause eggs or eggs cause chickens (Kellstedt, 2003). That makes sense for our analysis because we are not positing a mechanical connection of one domino hitting another, but rather a parallel dynamic responsiveness of bloggers (broadly defined) and professional journalists to public statements and events. The results of these regressions for the 29 issues are presented in Table 3.

The findings in Table 3 indicate that social media Granger cause higher levels of attention in traditional media in 18 of 29 tests, and traditional media Granger cause social media attention in 11 of 29 tests. In six cases, there is an evidence of mutual reciprocal Granger causation. This would appear to represent something of a challenge to the long celebrated notion of one-way media agenda-setting. For six of these policy issue clusters, the traditional media and the social media dynamics of attention appear to be entirely independent, with no evidence of Granger causation in either direction. Perhaps most surprising, given the established literature, is the prominence of the "reverse pattern" - the social-to-traditional media direction of Granger causality. It appears that the active public's response to events is more volatile and responds more immediately to events as the traditional media cover the story following journalistic routine and report each element of the story as it is available. Each responds to events according to its own dynamic of attention. Perhaps it is not that the journalists see that a story is "big on Twitter" and then mechanically produce additional stories for the wire or broadcast. In that sense, the social media are not "causing" traditional media issue attention. It may be more akin to a crowd going "Oh" when witnessing a significant event, and then some minutes later an Associated Press bulletin on the event hits the wires. The crowd did not cause the AP bulletin. Both crowds and the professional journalists are reacting to a shared perception that an event is significant and each is responding according to its own natural dynamic.

Interestingly, we find strong evidence of Granger causality from the social media to the traditional media for the issues of natural disasters, gun control, LGBT issues (lesbian, gay, bisexual, and transgender), and the Middle East/Arab Spring. This finding is in line with the results reported in Table 1, which shows that social media place heavier emphasis on social and public order issues relative to the traditional media. Because the digital citizenry has few independent sources, one might guess that the domains of economic policy and foreign affairs would provide the greatest evidence 
Table 3 Granger Analysis of Issue Trends in the Traditional and Social Media for 29 Issues - Calendar 2012

\begin{tabular}{|c|c|c|c|c|}
\hline \multirow[b]{2}{*}{ Issue Vectors } & \multicolumn{2}{|c|}{$\begin{array}{l}\text { Social to } \\
\text { Traditional Media }\end{array}$} & \multicolumn{2}{|c|}{$\begin{array}{l}\text { Traditional to } \\
\text { Social Media }\end{array}$} \\
\hline & $\begin{array}{l}\text { Chi } \\
\text { Square }\end{array}$ & $\begin{array}{c}p \\
\text { Value }\end{array}$ & $\begin{array}{l}\text { Chi } \\
\text { Square }\end{array}$ & $\begin{array}{c}p \\
\text { Value }\end{array}$ \\
\hline \multicolumn{5}{|l|}{ Economics } \\
\hline Unemployment/jobs & $15.8^{*}$ & .03 & 5.6 & 0.58 \\
\hline Economy/recession & 12.7 & .08 & 5.6 & 0.58 \\
\hline Deficit/national debt & $15.7^{*}$ & .03 & $17.9^{* *}$ & 0.01 \\
\hline Energy costs & $49.6^{* *}$ & .00 & $18.0^{* *}$ & 0.01 \\
\hline Finances/money/housing crisis & 10.6 & .16 & $19.2^{* *}$ & 0.01 \\
\hline Health care/costs/accessibility/Medicare/Medicaid & 8.3 & .30 & 1.0 & 1.00 \\
\hline Wall Street/corporate America & 4.8 & .68 & 4.9 & 0.68 \\
\hline Taxes/tax reform & $20.0^{* *}$ & .01 & 6.6 & 0.47 \\
\hline Welfare/uneven distribution of wealth/poverty & $24.6^{* *}$ & .00 & 4.9 & 0.68 \\
\hline \multicolumn{5}{|l|}{ Foreign affairs } \\
\hline War/Iraq War/Afghanistan War & $19.7^{* *}$ & .01 & 7.7 & 0.36 \\
\hline Terrorism & $24.3^{* *}$ & .00 & 4.5 & 0.72 \\
\hline Defense/national security & 11.2 & .13 & $25.1^{* *}$ & 0.00 \\
\hline Middle East/Arab spring & $59.4^{* *}$ & .00 & $14.1^{*}$ & 0.05 \\
\hline Global trade/China & $18.1^{* *}$ & .01 & 10.0 & 0.19 \\
\hline Immigration & 7.6 & .37 & 6.6 & 0.47 \\
\hline \multicolumn{5}{|l|}{ Government } \\
\hline Polarization/stalemate & $34.4^{* *}$ & .00 & $17.8^{* *}$ & 0.01 \\
\hline Lobbyists/special interests/campaign finance & 11.2 & .13 & 5.0 & 0.66 \\
\hline Education & $27.2^{* *}$ & .00 & 4.0 & 0.78 \\
\hline Emergency management/natural disasters & $96.7^{* *}$ & .00 & 11.1 & 0.13 \\
\hline \multicolumn{5}{|l|}{ Public order } \\
\hline Crime & 8.0 & .34 & $32.3^{* *}$ & 0.00 \\
\hline Drugs & 7.5 & .38 & $14.2^{*}$ & 0.05 \\
\hline Gun control/gun rights & $172.6^{* *}$ & .00 & $42.8^{* *}$ & 0.00 \\
\hline \multicolumn{5}{|l|}{ Social issues } \\
\hline Race/racism & 11.9 & .11 & 12.2 & 0.09 \\
\hline Gender/sexism & $21.3^{* *}$ & .00 & 8.9 & 0.26 \\
\hline LGBT & $85.1^{\star *}$ & .00 & $20.0^{* *}$ & 0.01 \\
\hline Abortion & 6.4 & .49 & 6.3 & 0.51 \\
\hline Birth control & 4.0 & .77 & 3.8 & 0.80 \\
\hline \multicolumn{5}{|l|}{ Environment } \\
\hline Environment & $19.9^{* *}$ & .01 & 6.9 & 0.44 \\
\hline Global warming & $24.5^{* *}$ & .00 & 2.1 & 0.96 \\
\hline
\end{tabular}

Note: Social media data are normalized (i.e., mean scaled) and summed. ${ }^{*} p<.05 .{ }^{* *} p<.01$. 
of traditional news spikes preceding the social media, but those are the areas in which the reverse direction was strongest. Ongoing research is attempting to assess whether these findings might be an artifact of the issues we chose or the particular news cycles of election year 2012 .

\section{When agendas diverge}

Visual inspection of the issue vectors for the traditional and social media draws attention to numerous cases when one vector spikes with often dramatically increased attention, while the other does not seem to react at all. Returning to the exemplary issue cluster of jobs/unemployment, we drilled down to examine the patterns for the Republican rhetoric for connecting taxation on wealthy Americans with depressed job growth, the widely touted notion of the wealthy as "job creators." Traditional media, for the most part, dutifully reported speeches and debate talking points which utilized the phrase and did so less often when liberals and Democrats might critique it. Although the social media often mechanically followed suit, we found a number of interesting cases of divergence as illustrated in Figure 2.

In the center of Figure 2 at point 192 (July 10), President Obama formally presented his tax plan, drawing attention to a central element of his campaign pledge "to have the wealthy pay their fair share" and excluding them for an extension of the Bush-era tax cuts. The Republican response was that this added insult to injury, by proposing to raise taxes on job creators while many Americans were still unemployed. This was a relatively high point of both social and traditional media attention. Upon closer inspection, we identified divergent patterns, as social memes (in this case most often critical of the Republican talking point) spiked in the social media. A case in point was the day after Thanksgiving, the "Black Friday" of intense Christmas shopping, when traditional media pumped out story after story from shopping malls while a relatively obscure cable commentary stated that "the real job creators are low-wage workers who spend every dime that they get." This commentary evolved into a social

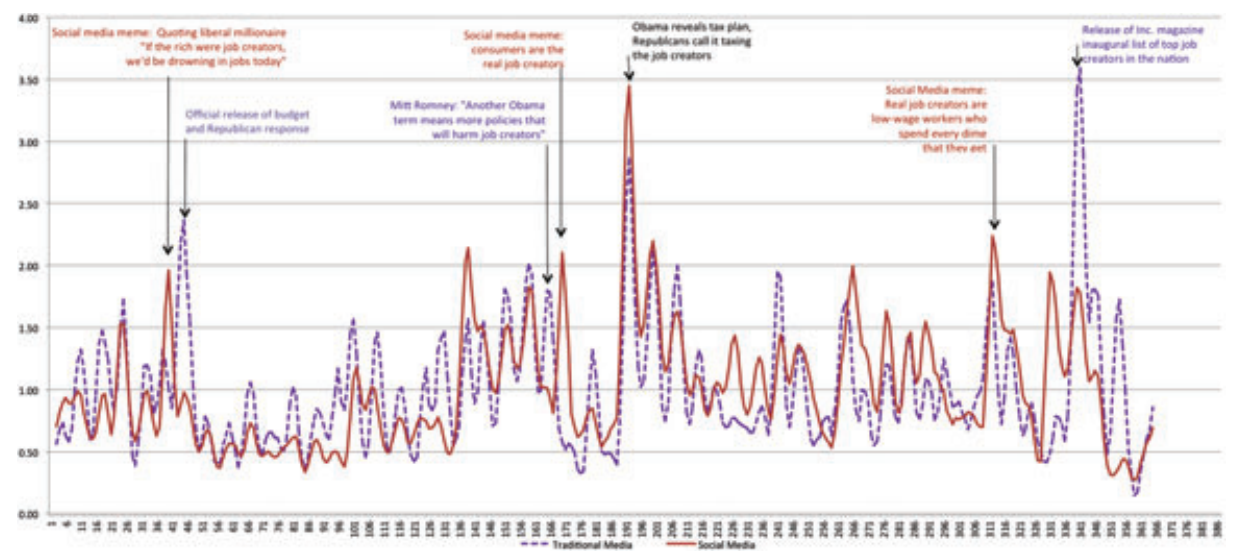

Figure 2 Trends in attention to "Job Creators" 2012. 
meme and soon took off like wildfire in the social media, with heavy citation and retweeting. Overall, the pattern was that traditional media, as expected, reported on the official and authoritative, such as the release of the federal budget, and social media follow along, some of the time with frequent exceptions of independent attentiveness. This provides further evidence for Lance Bennett's (1990) notion of media "indexing" (coverage of policy issues predominantly in terms of official sources), but suggests that the active public is nevertheless often independent minded in its framing of the policy debate at hand.

\section{Issue framing}

The capacity of Boolean search in big data to determine patterns of issue framing turns out to be somewhat more difficult than for issue attention. There are three reasons for this. First, while topical phrases such as "unemployment," "Afghanistan," and "same-sex marriage" are relatively straightforward and unambiguous, the rhetorical language engaged for issue evaluation, responsibility attribution, and political ideology is more subtle and complex. For example, assessing whether a blog post or news article attributes the primary responsibility for the housing crisis to irresponsible banks or irresponsible homeowners (or perhaps negligent regulators) is less easily determined by the frequency of reference to those respective elements of the story. Second, even when a clearly evaluative phrase such as "greedy banker" is used, it may be used satirically in a posting that is otherwise supportive of the banking industry and regulatory policy. Third, in the domain of political abstractions, a single term can manifest what are, in effect, polar opposite meanings. Thus, the term "capitalist" used by a conservative commentator refers to the benefits of free enterprise and entrepreneurs whereas to a liberal critic the term draws upon images of egregious profiteering and illicit back-room power politics.

Nonetheless, with appropriate prudence in execution of research designs and judiciousness in drawing conclusions, big data offer special promise for issue framing analysis. The key may be in identifying rarer elements of public rhetoric that clearly link to single frames of a more complex issue. Issue framing is important in understanding the potential dynamics of attention because the broadly defined issues of the day such as unemployment, immigration, abortion, and global warming have been around, and are likely to continue to be prominent in one form or another, in public debate for decades. As noted, many of the issues in our analysis were originally identified by the Michigan election studies in the 1950s. But issue framing is highly dynamic.

Table 4 provides some illustrative examples drawn from our 29-issue data set. For this analysis, we used short Boolean search phrases to represent two sides of an issue, searching the text for the same time period in the same media as our previous Granger analysis. For example, in the vocabulary of policy discussion the terminologies "prolife" and "prochoice" represent a longstanding and relatively unambiguous divide in how the question of abortion is addressed emphasizing, in turn, the life of the child and the choices of the mother. The "prolife" frame in 


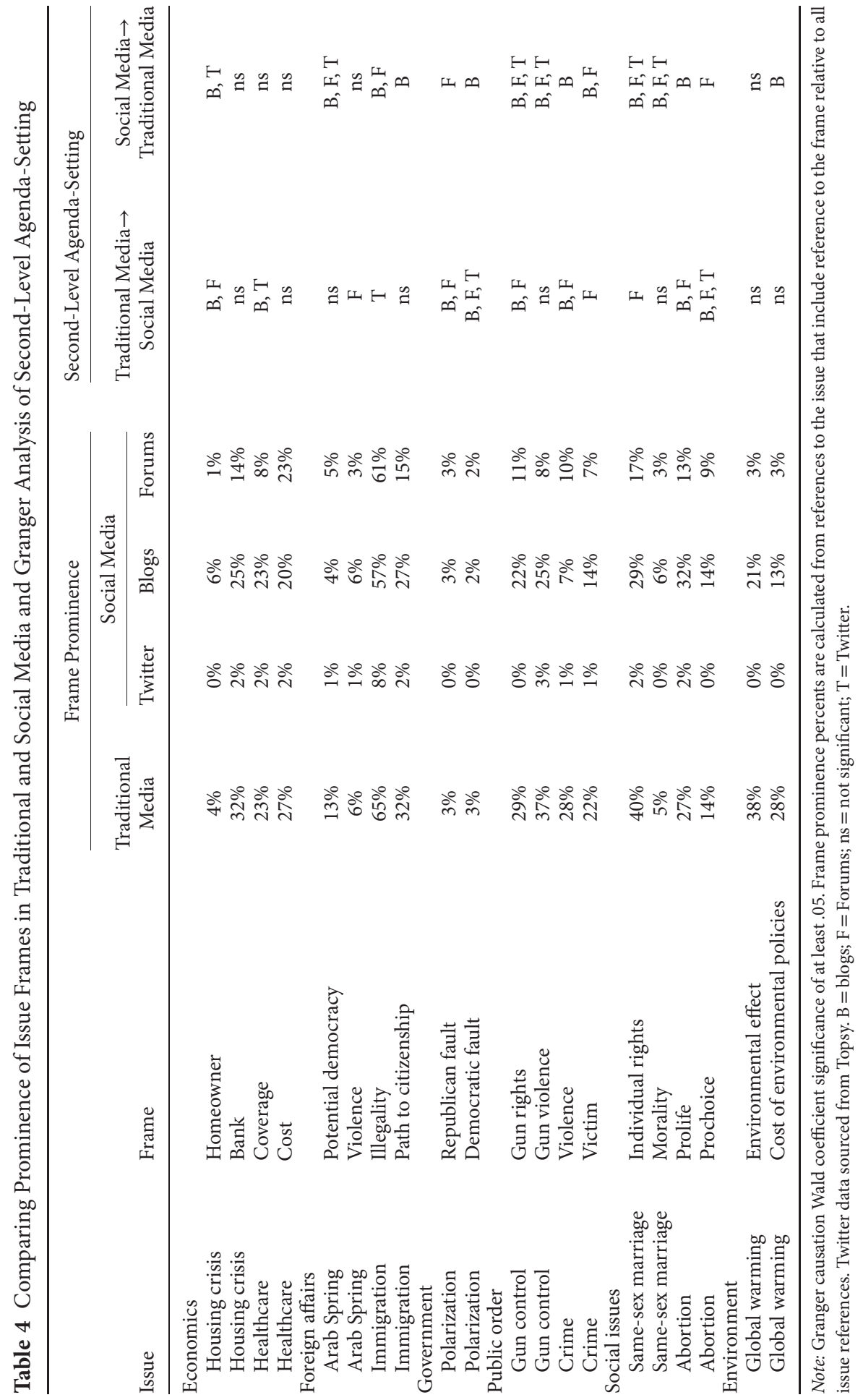


Table 4 is captured via a Boolean search of the phrase "abortion AND (prolife OR pro-life)" while "abortion AND (prochoice OR pro-choice)" was used to find the "prochoice" frames. Abortion was not a decisive federal or presidential campaign issue, but it generated periodic attention during a debate over private insurance coverage of abortion under the Affordable Care Act and at the state level as various conservative legislatures proposed laws to restrict late-term abortions. It is unlikely that variation in terminological emphasis changed deeply held views on this famously contentious issue, but clearly as events unfolded there was a reciprocal pattern of linkage between the traditional and social media. Our analysis of framing dynamics is reported in more detail elsewhere (Guggenheim, Neuman, Jang, \& Bae, 2014) but we see from Table 4 that the ratios of attention to issue frames in the traditional media and social media for the examples at hand (despite some variation) are roughly similar, and when differences arise they appear usually in but one of the social media under study. Further, we see again a rich mix of patterns of leading and lagging in the Granger analysis with no dominant pattern of agenda setting by one medium.

We draw four conclusions from this initial analysis of framing, which given space constraints just scratches the surface of the material at hand. First, as presented in Table 4, the percentages reflecting specific issue frames captured by our Boolean search phrases seem to represent a rather small percentage of the entire coverage in traditional and social media for each given issue (average 24\% of traditional, $2 \%$ of Twitter, 19\% of blogs, and 11\% of forums). Part of this, no doubt, results from our limited search phrases, which capture only some of the frame references. Yet the small average percentage of frames may provide evidence to support Iyengar's (1991) initial observation of media framing in general when he asks "Is anybody responsible?," noting how rarely and how often obliquely traditional media (and apparently social media) commentary deal with thematic, abstract, and structural issues, rather than concrete details of the episodic event at hand. Second, there is dramatic variation among the different social media under study. It becomes clear that the celebrated 140-character limit on tweets really does constrain the speaker, especially when it comes to more complex political issues and frames. Given that a large number of analysts have been drawn to the exclusive use of Twitter data in part because, unlike many other social media sites, most tweets are publicly available, it signals caution for those who might unthinkingly equate patterns in the Twitterverse with the rest of social media. Third, again we see a complex and dynamic pattern of leading and lagging indicators among the social and traditional media rather than a dominance of traditional media agenda setting in the electronic public sphere. Fourth, and finally, a caveat of caution - all of the issue spikes and trends in the analysis have been limited to the brief window of calendar 2012. The literature is clear that the ups and downs of a few weeks and months can accumulate over the years and decades to significant changes in public perceptions and even more broadly defined ideological bearing points so we are examining a limited snapshot of broader terrain (Erikson, MacKuen, \& Stimson, 2002; Page \& Shapiro, 1991). 


\section{Discussion}

In the opening paragraphs of this report, we referred to those drawing attention to new directions in big data analysis as full of enthusiasm and perhaps a bit of missionary zeal. Such a response is understandable and perhaps a bit contagious. Our experience with these resources has raised some challenges to well-accepted findings, confirmed other findings, and raised many new questions. In contrast to surveys and experiments, when an anomalous finding occurs in big data, one can drill down into the database and examine news stories and blog posts to better understand the nature of an attentional spike or shifting issue frame; it is not always necessary to return to the field or laboratory with a new research design to try to resolve the anomaly. Perhaps more importantly, new formats of data representing human communication stimulate new paradigmatic puzzles, acknowledging Thomas Kuhn's often cited insight that the scientific puzzle and the methodology designed to solve the puzzle are intimately linked (Kuhn, 1962). Big data methodologies do not represent a panacea or a substitute for carefully designed surveys, experiments, and content analyses. Instead they represent a complement, an additional resource for better understanding a fast-changing electronic public sphere.

Our primary finding was a demonstration of the abundant evidence that the public agenda as reflected in the social media is not locked in a slavish or mechanical connection to the news agenda provided by the traditional news media. The social media spend a lot more time discussing social issues such as birth control, abortion, and same-sex marriage and public order issues such as drugs and guns than the traditional media. And they are less likely to address issues of economics (especially economic policy) and government functioning. Interestingly, the blogs are alive with the sound of foreign affairs, which is traditionally characterized as of limited interest to the general public (Holsti, 2004). This may result in our case from public resonance with developments in the Arab Spring and the immigration policy debate central to the evolving political campaigns of 2012 as noted in Table 1. The overall temporal correlation of issue attention averaged about .50 indicating approximately $25 \%$ common variance - the rest is independent variance and probably a fair amount of measurement noise. But the demonstration of independent attentional variance is important.

Moreover, the attentional spikes of the blogs, tweets, and discussion board posts are as likely to precede the traditional media as to follow it. The logic of traditional Granger analyses calls for a test of whether $x$ Granger causes $y$ and whether $y$ Granger causes $x$. So the question of who sets the agenda in this approach to our puzzle permits the prospect of mutual and reciprocal "causality" - in some cases, that is precisely what we found. Overall, evidence showed Granger causality in a single direction for roughly half of our 29 issues and reciprocity occurred for one issue vector in five. Likewise, we have reviewed several patterns of issue framing in the social and traditional media and they confirm our general theme of interdependence of the two, rather than one-way agenda-setting, as best we can assess it by Boolean search. Further research will allow us to explore under what conditions increasing emphases on particular issue 
frames in the traditional media do or do not correspond to similar framing emphasis in the social media, and, of course, the reverse. In both the matter of spikes of attention and of issue framing, some of our conclusions thus far may depend on the issues we have selected, the search phrases we have chosen, and the time frame of calendar 2012. Both the traditional media, under increasing economic pressures, and the social media, whose technical platforms and social cultures continue to evolve, are subject to dramatic change which could influence these dynamics.

We posited our research questions in the traditional form derived from the agenda-setting literature - who sets the media agenda? But upon further reflection, the question seems ill structured. The relationship between political discussion in traditional commercial media and social media, we argue, is better characterized as an interaction and differentiated resonance as each in its own way responds to the events of the day rather than a mechanical causal linkage. Bloggers are as likely to pick up on an issue or event from another blogger as they are from a professional newspaper editorial writer or a news anchor. Our unit of temporal analysis was the 24-hour day. Clearly some of the dynamics we confront here happen in a matter of minutes rather than days, so we were limited to examining more temporally macro phenomena in this analysis.

We began with questions derived from the literature on media effects, public opinion, and public attention, mostly structured in terms of causal direction. Our explorations of big data, however, forced us to rethink the questions themselves. The analysis proceeds as a comparison of how the traditional media and the social media, each with their own characteristic resonance, respond dynamically in intertwined interactivity to the issues and current events. A question of mechanical causation or a singular causal direction would seem to be somewhat beside the point. And, importantly, social media provide ample evidence that their characteristic issue attentiveness and issue framing are not slavishly dependent upon, but rather quite independent of, the voice of the traditional media, official institutional spokespersons, and professional journalism.

It is still early in the exploration of big data to test and refine social science theory. Our methods may still be in development and standards for evaluating scholarship not yet mature. We have aspired to demonstrate that not only can big data be put to work to respond directly and decisively to important theories and hypotheses in public communication and media effects, but it can serve to refine how the questions themselves are formulated.

\section{References}

Bansal, N., \& Koudas, N. (2007). BlogScope: Spatio-temporal analysis of the blogosphere.

Proceedings of WWW 2007, 1269-1270. Retrieved from http://www2007.org/posters/ poster908.pdf

Becketti, S. (2013). Introduction to time series using Stata. College Station, TX: Stata Press.

Bennett, W. L. (1990). Toward a theory of press-state relations in the United States. Journal of

Communication, 40(2), 103-127. doi:10.1111/j.1460-2466.1990.tb02265.x.

Blogpulse. (2011). blogpulse.com NM Incite. 
Bollier, D. (2010). The promise and peril of big data. Washington, DC: Aspen Institute.

Borrero, J. D., \& Gualda, E. (2013). Crawling big data in a new frontier for socioeconomic research: Testing with social tagging. Journal of Spatial and Organizational Dynamics -Discussion Papers Number 12. Retrieved from: http://www.cieo.pt/ discussionpapers/12/article1.pdf

Boyd, D., \& Crawford, K. (2012). Critical questions for big data. Information, Communication and Society, 15(5), 662-679. doi:10.1080/1369118x.2012.678878.

Brosius, H. B., \& Kepplinger, H. M. (1990). The agenda-setting function of television news. Communication Research, 17(2), 183-211. doi:10.1177/009365090017002003.

Burstein, P. (1985). Discrimination, jobs, and politics: The struggle for equal opportunity in the United States since the New Deal. Chicago, IL: University of Chicago Press.

Chaffee, S. H. (1972). Longitudinal designs for communication research: Cross-lagged correlations. Paper presented to the Annual Conference of the Association for Education in Journalism, Carbondale, IL.

Chong, D. (1993). How people think, reason, and feel about rights and liberties. American Journal of Political Science, 37(3), 867 -899. doi:10.2307/2111577.

Chong, D., \& Druckman, J. N. (2007). Framing theory. Annual Review of Political Science, 10(1), 103 - 126. doi:10.1146/annurev.polisci.10.072805.103054.

Cohen, B. C. (1963). The press and foreign policy. Princeton, NJ: Princeton University Press.

Cohen, J. E. (2008). The presidency in the era of 24-hour news. Princeton, NJ: Princeton University Press.

Dearing, J. W., \& Rogers, E. M. (1996). Agenda-setting. Thousand Oaks, CA: Sage.

Denham, B. E. (2010). Toward conceptual consistency in studies of agenda-building processes: A scholarly review. The Review of Communication, 10(4), 306-323. doi:10.1080/15358593.2010.502593.

Druckman, J. N., \& Nelson, K. R. (2003). Framing and deliberation: How citizens' conversations limit elite influence. American Journal of Political Science, 47, 728 - 744. doi:10.1111/1540-5907.00051.

Entman, R. M. (1993). Framing: Toward clarification of a fractured paradigm. Journal of Communication, 43(4), 51-58. doi:10.1111/j.1460-2466.1993.tb01304.x.

Entman, R. M. (2004). Projections of power: Framing news, public opinion, and U.S. foreign policy. Chicago, IL: University of Chicago Press.

Erikson, R. S., MacKuen, M., \& Stimson, J. A. (2002). The macro polity. New York, NY: Cambridge University Press.

Fan, D. P. (1988). Predictions of public opinion from the mass media. Westport, CT: Greenwood.

Freeman, J. R. (1983). Granger causality and the times series analysis of political relationships. American Journal of Political Science, 27(2), 327.

Gamson, W. A. (1992). Talking politics. New York, NY: Cambridge University Press.

Gilens, M. (1999). Why Americans hate welfare: Race, media and the politics of antipoverty policy. Chicago, IL: University of Chicago Press.

Golan, G. (2006). Inter-media agenda setting and global news coverage: Assessing the influence of the New York Times on three network television evening news programs. Journalism Studies, 7(2), 323-333. doi:10.1080/14616700500533643.

Granger, C. W. J. (1969). Investigating causal relations by econometric models and cross-spectral methods. Econometrica, 37(3), 424-438. doi:10.2307/1912791. 
Guggenheim, L., Neuman, W. R., Jang, S. M., \& Bae, S. Y. (2014). The dynamics of issue frame competition in traditional and social media. Working paper, University of Michigan, Ann Arbor, MI.

Habermas, J. (1962). The structural transformation of the public sphere. Cambridge, MA: MIT Press.

Haskins, W. (2007). Bloggers' greatest hits, Vol. 1. TechNewsWorld. Retrieved from: http:// www.technewsworld.com/story/58038.html

Hindman, M. S. (2009). The myth of digital democracy. Princeton, NJ: Princeton University Press.

Holsti, O. R. (2004). Public opinion and American foreign policy. Ann Arbor, MI: University of Michigan Press.

Iyengar, S. (1991). Is anyone responsible? How television frames political issues. Chicago, IL: University of Chicago Press.

Karpf, D. (2008). Measuring influence in the political blogosphere. Politics and Technology Review, 33-41.

Katz, E., \& Lazarsfeld, P. F. (1955). Personal influence: The part played by people in the flow of communications. New York, NY: Free Press.

Kellstedt, P. M. (2003). The mass media and the dynamics of American racial attitudes. New York, NY: Cambridge University Press.

Kelly, R. (2009, August 12). Twitter study. San Antonio, TX: Pear Analytics. Retrieved from http://www.pearanalytics.com/wp-content/uploads/2012/12/TwitterStudy-August-2009.pdf

Kim, S.-T., \& Lee, Y.-. H. (2006). New functions of Internet mediated agenda-setting: Agenda-rippling and reversed agenda-setting. Korean Journal of Journalism and Communication Studies, 50(3), 175-205.

Klapper, J. (1960). The effects of mass communication. New York, NY: Free Press.

Kuhn, T. (1962). The structure of scientific revolutions. Chicago, IL: University of Chicago Press.

Lee, J. K. (2007). The effect of the Internet on homogeneity of the media agenda: A test of the fragmentation thesis. Journalism and Mass Communication Quarterly, 84(4), 745-760. doi:10.1177/107769900708400406.

Lenhart, A., \& Fox, S. (2006). Bloggers: A portrait of the internet's new storytellers. Retrieved from: http://www.pewinternet.org/ /media/Files/Reports/2006/PIP\%20Bloggers\%20 Report\%20July\%2019\%202006.pdf.

McCombs, M. (2004). Setting the agenda: The mass media and public opinion. Cambridge, UK: Polity.

McCombs, M. E., \& Shaw, D. L. (1972). The agenda-setting function of the mass media. Public Opinion Quarterly, 36, 176-187. doi:10.1086/267990.

McCombs, M. E., \& Shaw, D. L. (1993). The evolution of agenda-setting research: Twenty-five years in the marketplace of ideas. Journal of Communication, 43(2), 58-67. doi:10.1111/j.1460-2466.1993.tb01262.x.

McCombs, M., Shaw, D. L., \& Weaver, D. H. (1997). Communication and democracy: Exploring the intellectual frontiers in agenda-setting theory. Mahwah, NJ: Erlbaum.

Neuman, W. R. (1990). The threshold of public attention. Public Opinion Quarterly, 54(2), $159-176$.

Page, B. I., \& Shapiro, R. Y. (1991). The rational public: Fifty years of trends in Americans' policy preferences. Chicago, IL: University of Chicago Press. 
Roberts, M., Wanta, W., \& Dzwo, T. H. (Dustin). (2002). Agenda setting and issue salience online. Communication Research, 29(4), 452-465. doi:10.1177/0093650202029004004.

Seth, A. (2007). Granger causality. Scholarpedia, 2(7), 1667.

Shah, D. V., Watts, M. D., Domke, D., \& Fan, D. P. (2002). News framing and cueing of issue regimes: Explaining Clinton's public approval in spite of scandal. Public Opinion Quarterly, 66(3), 339-370. doi:10.1086/341396.

Shoemaker, P. J., \& Reese, S. D. (2014). Mediating the message in the 21st century: A media sociology perspective. New York, NY: Allyn and Bacon.

Taylor, C. (2011, September 8). Twitter has 100 million active users. Retrieved from Mashable.com.

Wallsten, K. (2007). Agenda setting and the blogosphere: An analysis of the relationship between mainstream media and political blogs. Review of Policy Research, 24(6), 567-587. doi:10.1111/j.1541-1338.2007.00300.x.

Wanta, W. (1997). The public and the national agenda: How people learn about important issues. Mahwah, NJ: Erlbaum.

Wanta, W., \& Ghanem, S. (2007). Effects of agenda setting. In R. W. Preiss, B. M. Gayle, N. Burrell, M. Allen, \& J. Bryant. (Eds.), Mass media effects research: Advances through meta-analysis (pp. 37-52). Mahwah NJ: Erlbaum.

Wanta, W., \& Hu, Y.-W. (1994). Time-lag differences in the agenda-setting process: An examination of five news media. The International Journal of Public Opinion Research, 6(3), 225-240. doi:10.1093/ijpor/6.3.225.

Wiener, N. (1956). The theory of prediction. In F. E. Beckenbach (Ed.), Modern mathematics for engineers. New York, NY: McGraw Hill.

Zaller, J. (1992). The nature and origins of mass opinion. New York, NY: Cambridge University Press. 